\title{
The association of pulmonary function, physical activity, cardiorespiratory fitness, Borg dyspnea scales and health related quality of life in patients with resected lung cancer
}

\section{Xinping Li}

Guangdong Provincial People's Hospital

Yi Chen

Shenzhen Children's Hospital

Shuangchun Liu

Southern Medical University

Mingsheng Zhang ( $\square$ mszrch@163.com)

Guangdong Provincial People's Hospital https://orcid.org/0000-0002-8477-6783

\section{Research}

Keywords: Relationship, lung cancer, quality of life, direct effect, cardiorespiratory fitness

Posted Date: May 26th, 2021

DOl: https://doi.org/10.21203/rs.3.rs-543131/v1

License: (c) (1) This work is licensed under a Creative Commons Attribution 4.0 International License.

Read Full License 


\section{Abstract \\ Background}

Understanding the determinants of quality of life for the patients after lung resection would be beneficial to affect the prevention programs and the treatment strategies. This novel study aims to explore the relationship between pulmonary function, physical activity, cardiorespiratory fitness (CRF), dyspnea, and the health-related quality of life (HRQoL) of patients with resected lung cancer.

\section{Methods}

A cross-sectional study design with 38 lung cancer survivors after surgery for one month was conducted. We assessed $\mathrm{CRF}$ by measuring maximal oxygen consumption $\left(\mathrm{VO}_{2 \mathrm{max}}\right)$ and anaerobic threshold (VT).Forced vital capacity (FVC) was measured using a spirometer. Physical activity, dyspnea, and HRQoLwereinvestigated by 6-minute walking distance (6MWD), Borg dyspnea scales, and the SF-36 Health Survey (SF-36), respectively.Data analyses were conducted using SmartPLS to examine path analyses between the measures.

\section{Results}

There was a significant relationship between CRF andHRQoL in this cohort of cancer survivors.FVC $\left(f^{2}=\right.$ $0.265)$ and $6 \mathrm{MWD}\left(\mathrm{f}^{2}=0.389\right)$ have a medium to large effect size on the perceived CRF while CRF $\left(\mathrm{f}^{2}=\right.$ $0.467)$ was found to have large effect sizes on perceived QoL. More importantly, our results showed that CRF positively and significantly mediated the paths betweenFVC, $6 \mathrm{MWD}$, andHRQoL[ $\beta=0.22$ $(0.457 * 0.474), P<0.01 ; \beta=0.28(0.525 * 0.540), P<0.01$; respectively $]$.

\section{Conclusions}

Pulmonary function, physical activity, and dyspnea had an indirect effect on the quality of life in patients with resected lung cancer. Furthermore, CRF mediates pulmonary function and physical activity to produces an impact on their quality of life.

\section{Introduction}

Much progress has been made in the diagnosis and treatment for non-small cell lung cancer in recent years, and the prognosis gradually improves corresponding. For a significant number of patients, surgical resection is the preferred therapeutic method. Unfortunately, the survival rate following an operation is not satisfactory, more and more patients acquire prolonged postoperative survival [1], and improving quality of life (QoL) for those patients is also important [2]. 
lung resection has a significant short- and long-term impact on pulmonary function and oxygenation [3], and physical activities, measured by 6-minute walking distance (6MWD), were also reported to decline after surgery [4]. And many symptoms including dyspnea, emotional, pain, and side effects of treatment may occur after lung resection. Meanwhile, good quality of life after surgery is one of the main goals of comprehensive treatment. However, lung resection is so invasive that it lowers QoL, especially, in the early period after surgical treatment [5]. Unfortunately, a limited number of studies have examined the relationship between pulmonary function, cardiorespiratory fitness (CRF), physical activities, dyspnea, and QoL.

Many pieces of evidence showed that the symptoms are involved in the quality of life. For instance, the previous study showed that there was a strong association between the peak oxygen uptakeand 6MWD in adults with achondroplasia [6]. Engberg et al. found that CRT was positively associated with healthrelated QoL in women at risk for gestational diabetes [7]. And Ha D et al. reported that exercise capacity was independently associated with QoL for lung cancer patients after post-curative-intent treatment [8]. Based on those results, we hypothesized that pulmonary function, CRF, physical activities, and dyspnea can influence QoL in patients with resected lung cancer.

Understanding the determinants of QoL for the patients after lung resection would be beneficial to affect the prevention programs and the treatment strategies. In this study, we investigate the association between pulmonary function, CRF, physical activities, dyspnea, and QoL in patients after lung resection and validate our proposed model.

\section{Patients And Methods}

Study design and population

A cross-sectional study was designed. This study was performed according to the declaration of Helsinki and was approved by the Guangdong provincial people's Hospital.

The patients who underwent a lobectomy or a segmentectomy were recruited following the criteria were non-small-cell lung cancer staged T1, T2, and T3a with or without COPD. The Exclusion factors included: non-small-cell lung cancer staged T3b and T4, associated with other serious chronic diseases; refused to participatein this study.

\section{Protocol}

Each patient had a routine full clinical assessment before the inclusion process, and all patients included in the present study provided written informed consent before data collection. The assessments including QoL, CRF, pulmonary function, physical activities, and dyspnea were performed one month after lung resection. Data were collected from February 2015 to November 2018.

Health-related QoL (HRQoL) 
We assessed HRQoL with a 36-item short-formhealth survey V1 (SF-36) [9]. The survey is a valid and reliable 36-item questionnaire that is widely used to measure QoL. It yields two summary scores of physical (Physical Functioning, Role-Physical, Bodily Pain, and General Health) and mental (Vitality, Social Functioning, Mental Health, and Role-Emotional) health. The scales range from 0 to 100, with 0 indicating the worst situation and 100 indicating the best situation in each domain.

\section{CRF}

A physician examined the patients beforehand to ensure their suitability to perform the test. We assessed CRF by measuring maximal oxygen consumption $\left(\mathrm{VO}_{2 \mathrm{max}}\right)$ and anaerobic threshold (VT) in incremental (30W/3min) cycle ergometer exercise (Metamax 3B, Cortex, Germany) until patient fatigue. $\mathrm{VO}_{2 \mathrm{max}} \mathrm{Was}$ determined as the highest 1-minute average value and was normalized for body mass $\left(\mathrm{mL} \cdot \mathrm{kg}^{-1} \cdot \mathrm{min}^{-1}\right)$.

Pulmonary function

Pulmonary volumes including forced vital capacity (FVC) and forced expiratory volume at 1 second $\left(\mathrm{FEV}_{1}\right)$ were measured using a spirometer (Electgraph HI-101, CHEST, Tokyo, Japan), and corrected for temperature and barometric pressure, according to the American Thoracic Society recommendations [10]. Each patient performed at least three trials and the best performance was used for analysis. Because QoL had a poor correlation with $\mathrm{FEV}_{1}$ [11], we choose FVC for the statistical analysis.

Physical activities

Physical activity was determined by 6-MWD [12]. 6-MWD was carried out under the same conditions. Patients were instructed to walk at their fastest pace to cover the longest possible distance over 6 min. The longest walk was taken to represent the value.

Borg dyspnea scale

Prior to pulmonary function testing, the patients were requested to quantify their sensation of dyspnea by pointing to a score on the Borg scale category ratio 10 (CR10).

\section{Statistical analysis}

Data were expressed as the mean values \pm SD for ordinal or continuous variables, and as numbers and percentages for categorical variables. Statistical analysis was performed using GraphPad Prism software version 8.0 for Windows (GraphPad Software, San Diego, California, USA), and SMARTPLS 3.0 was used to run confirmatory factor analysis (CFA) and to verify the internal consistency, reliability, and validity of the theoretical model. We examined whether the variables were normally distributed with the Andersondarling test, then we used Spearman's correlation coefficients (Rs) for non-normally distributed variables. For normally distributed variables, we used Pearson's correlation coefficients (Rp). Finally, the structural model was estimated and used SmartPLS to examine path analyses between the measures., and the proposed hypotheses were confirmed. 


\section{Results}

Clinical characteristics

Table 1 summarizes the characteristics, CRF, HRQoL, FVC, 6MWD, and Borg dyspnea scales of the patients. 31 patients underwent a lobectomy, and 7 patients had a segmentectomy. All of the patients did not perform the preoperative treatment, and the TNM classification of the lung cancers were as following: 24 stages 1, 10 stages 2 , and 4 stages 3 a. The types of lung cancer cells were as follows: 22 adenocarcinomas, 13 squamous carcinomas, and 3 others.

Table 1

Thepatients' clinical characteristics and functional variables in patients with lung cancer resection $(n=$ 38)

\begin{tabular}{|c|c|c|c|}
\hline Variables & $\begin{array}{l}\text { Gender/mean } \pm \\
\text { SD }\end{array}$ & Variables & Mean \pm SD \\
\hline Sex (males/females) & $22 / 16$ & V02max & $\begin{array}{l}16.95 \pm \\
4.12\end{array}$ \\
\hline Age, years & $63.93 \pm 8.75$ & VT & $\begin{array}{l}11.42 \pm \\
2.87\end{array}$ \\
\hline BMI & $22.33 \pm 2.84$ & $6 \mathrm{MWD}$ & $\begin{array}{l}477.3 \pm \\
67.92\end{array}$ \\
\hline Smoking history (No/Yes) & $28 / 10$ & FVC & $1.86 \pm 0.63$ \\
\hline Histological type (Ad/Sc/other) & $22 / 13 / 3$ & Borg scales & $1.07 \pm 0.53$ \\
\hline Pathological stage (I/II/III) & $24 / 10 / 4$ & HRQoL & $\begin{array}{l}50.81 \pm \\
14.06\end{array}$ \\
\hline \multirow[t]{2}{*}{$\begin{array}{l}\text { Surgery (a lobectomy or a } \\
\text { segmentectomy) }\end{array}$} & $31 / 7$ & $\begin{array}{l}\text { Physical Component } \\
\text { Summary }\end{array}$ & $\begin{array}{l}23.52 \pm \\
7.59\end{array}$ \\
\hline & & $\begin{array}{l}\text { Mental Component } \\
\text { Summary }\end{array}$ & $\begin{array}{l}27.29 \pm \\
7.32\end{array}$ \\
\hline
\end{tabular}

Correlation matrix

The correlation matrix of CRF, FVC, 6MWD, Borg dyspnea scales and HRQoL were shown in Table 2. $\mathrm{VO}_{2 \max }$ and VT were positively associated with 6 out of 8 domain scales of the SF-36. FVC was positively associated with the role-Emotional, vitality, and general health scales of the SF-36. Borg dyspnea scales were negatively associated with the physical functioning, physical functioning, and mental health scales of the SF-36. And 6MWD was positively associated with the physical functioning, mental health, and social functioning scales of the SF-36. 
Table 2

Correlation coefficients of FVC, AT, V02max, 6MWD, and Borg scales with health-related quality of life (SF-36)

\begin{tabular}{|c|c|c|c|c|c|}
\hline Domains & FVC & AT & $\mathrm{VO}_{2 \max }$ & 6MWD & Borg scales \\
\hline $\begin{array}{l}\text { Physical } \\
\text { Functioning }\end{array}$ & $\begin{array}{l}\text { Rs }=0.144, P \\
=0.388\end{array}$ & $\begin{array}{l}\text { Rs }=0.448, P \\
=0.005\end{array}$ & $\begin{array}{l}\text { Rs }=0.474, P \\
=0.003\end{array}$ & $\begin{array}{l}\text { Rs }=0.427, P \\
=0.008\end{array}$ & $\begin{array}{l}\text { Rs }=-0.346, \mathrm{P} \\
=0.033\end{array}$ \\
\hline Role-Physical & $\begin{array}{l}\text { Rs }=0.185, P \\
=0.266\end{array}$ & $\begin{array}{l}\text { Rs }=0.430, P \\
=0.007\end{array}$ & $\begin{array}{l}\text { Rs }=0.515, P \\
=0.001\end{array}$ & $\begin{array}{l}\text { Rs }=0.448, P \\
=0.005\end{array}$ & $\begin{array}{l}\text { Rs }=-0.432, P \\
=0.007\end{array}$ \\
\hline Bodily Pain & $\begin{array}{l}\text { Rs }=0.205, P \\
=0.217\end{array}$ & $\begin{array}{l}\text { Rs }=0.181, P \\
=0.277\end{array}$ & $\begin{array}{l}\text { Rs }=0.203, P \\
=0.222\end{array}$ & $\begin{array}{l}\text { Rs }=0.065, P \\
=0.697\end{array}$ & $\begin{array}{l}\text { Rs }=-0.029, \mathrm{P} \\
=0.865\end{array}$ \\
\hline $\begin{array}{l}\text { General } \\
\text { Health }\end{array}$ & $\begin{array}{l}\mathrm{Rp}=0.432, \mathrm{P} \\
=0.0068\end{array}$ & $\begin{array}{l}\mathrm{Rp}=0.047, \mathrm{P} \\
=0.782\end{array}$ & $\begin{array}{l}\mathrm{Rp}=0.254, \mathrm{P} \\
=0.124\end{array}$ & $\begin{array}{l}\mathrm{Rp}=0.137, \mathrm{P} \\
=0.4117\end{array}$ & $\begin{array}{l}\text { Rs }=-0.105, P \\
=0.531\end{array}$ \\
\hline Vitality & $\begin{array}{l}\text { Rs }=0.566, P \\
=0.000\end{array}$ & $\begin{array}{l}\text { Rs }=0.435, P \\
=0.006\end{array}$ & $\begin{array}{l}\text { Rs }=0.393, P \\
=0.015\end{array}$ & $\begin{array}{l}\text { Rs=-0.065, } P \\
=0.700\end{array}$ & $\begin{array}{l}\text { Rs }=0.083, \mathrm{~F} \\
=0.621\end{array}$ \\
\hline $\begin{array}{l}\text { Social } \\
\text { Functioning }\end{array}$ & $\begin{array}{l}\text { Rs }=0.123, \mathrm{P} \\
=0.461\end{array}$ & $\begin{array}{l}\text { Rs }=0.522, \mathrm{P} \\
=0.001\end{array}$ & $\begin{array}{l}\text { Rs }=0.421, \mathrm{P} \\
=0.008\end{array}$ & $\begin{array}{l}\text { Rs }=0.367, \mathrm{P} \\
=0.023\end{array}$ & $\begin{array}{l}\text { Rs }=-0.230, P \\
=0.166\end{array}$ \\
\hline $\begin{array}{l}\text { Mental } \\
\text { Health }\end{array}$ & $\begin{array}{l}\text { Rs }=0.111, P \\
=0.507\end{array}$ & $\begin{array}{l}\text { Rs }=0.368, P \\
=0.029\end{array}$ & $\begin{array}{l}\text { Rs }=0.334, P \\
=0.0404\end{array}$ & $\begin{array}{l}\text { Rs }=0.328, P \\
=0.045\end{array}$ & $\begin{array}{l}\text { Rs }=-0.444, \mathrm{P} \\
=0.005\end{array}$ \\
\hline $\begin{array}{l}\text { Role- } \\
\text { Emotional }\end{array}$ & $\begin{array}{l}\mathrm{Rp}=0.402, \mathrm{P} \\
=0.0124\end{array}$ & $\begin{array}{l}\mathrm{Rp}=0.369, \mathrm{P} \\
=0.0225\end{array}$ & $\begin{array}{l}\mathrm{Rp}=0.482, \mathrm{P} \\
=0.0022\end{array}$ & $\begin{array}{l}\mathrm{Rp}=0.197, \mathrm{P} \\
=0.2367\end{array}$ & $\begin{array}{l}\text { Rs }=-0.169, \mathrm{P} \\
=0.310\end{array}$ \\
\hline Summary & $\begin{array}{l}\mathrm{Rp}=0.300, \mathrm{P} \\
=0.0672\end{array}$ & $\begin{array}{l}\mathrm{Rp}=0.412, \mathrm{P} \\
=0.0102\end{array}$ & $\begin{array}{l}\mathrm{Rp}=0.490, \mathrm{P} \\
=0.0018\end{array}$ & $\begin{array}{l}\mathrm{Rp}=0.328, \mathrm{P} \\
=0.044\end{array}$ & $\begin{array}{l}\text { Rs }=-0.348, F \\
=0.032\end{array}$ \\
\hline
\end{tabular}

Evaluation of the structural model

Table 3 and Fig. 1 showed that the hypothesis model was supported and indicated an acceptable model fit. The $\mathrm{R}^{2}$ value for QoL construct is 0.385 which means $38.5 \%$ of the changes in QoLwere due to pulmonary function, cardiorespiratory fitness, physical activities, and dyspnea in the model (Fig. 1). The path linking CRF to the perceived QoL was positive and statistically significant, and the path linking FVC, 6MWD, and Borg scales to QoL was not positive and statistically insignificant (Fig. 1). We foundthatFVC $\left(f^{2}=0.265\right)$ and 6MWD $\left(f^{2}=0.389\right)$ have a medium to large effect size on the perceived CRF while CRF was found to have large effect sizes on perceived QoL (Table 4). 
Table 3

Summary of structural model hypotheses

\begin{tabular}{|c|c|c|c|c|}
\hline Path & Path coefficients & t-value & Sig. & Inference \\
\hline $\mathrm{Dy} \square \mathrm{PC}$ & -0.528 & 5.511 & 0.000 & Supported \\
\hline CRFロQoL & 0.564 & 6.999 & 0.000 & Supported \\
\hline $\mathrm{PC} \square \mathrm{CRF}$ & 0.476 & 3.937 & 0.000 & Supported \\
\hline PFICRF & 0.393 & 3.069 & 0.002 & Supported \\
\hline
\end{tabular}

Table 4

Results of effect size $\mathrm{f}^{2}$ analysis

\begin{tabular}{|lllll|}
\hline Dependent construct & Independent construct & $\mathbf{R}^{\mathbf{2}}$ & $\mathbf{f}^{\mathbf{2}}$ & Inference \\
\hline QoL & CRF & 0.318 & 0.467 & Large \\
\hline CRF & PF & 0.425 & 0.265 & Medium to large \\
\cline { 2 - 4 } & PC & & 0.389 & Large \\
\hline PC & Dy & 0.278 & 0.386 & Large \\
\hline
\end{tabular}

Dy, dyspnea; PC, physical capacity; CRF, cardiorespiratory fitness; PF, pulmonary function; QoL, quality of life

Result for mediation test

According to the views from Preacher and Hayes [13],the path model for the relationships between physical activities $(\beta=0.441, P<0.05)$, pulmonary function $(\beta=0.462, P<0.05)$, dyspnea $(\beta=0.491, P<$ $0.05)$, and QoLwere statistically significant. However, after adjusting the indirect effects of the mediator, the direct effect of physical activities $(\beta=0.045, P>0.05)$, pulmonary function $(\beta=0.190, P>0.05)$ or dyspnea $(\beta=0.19, P>0.05)$ on HRQoL was no longer significant, as shown in Fig. $2-4$. The indirect effects indicate that there is a mediation. Figure 4 depicts that pulmonary function or physical activities was positively related to engagement in CRF, which in turn was significantly related to QoL (Fig. 2,4). And Borg scales need to be positively related to physical activities, then significantly related to CRF and QoL (Fig. 3).

\section{Discussion}

This study used the path-analyses method to examine the relationship between CRF, FVC, 6MWD, Borg scale, and health-related QoL in patients with lung resection. Our results showed that FVC was poor correlated with QoL. And Bog scales were a strong correlation with physical activities only. Though 
6MWD and FVC were positively associated with QoL, an insignificant direct effect between QoL with FVC or 6MWD was observed. Our findings also showed that CRT was a strong correlation with QoL, and took charge of $38.4 \%$ of the changes in the perceived quality of life in the model. CRF as a mediator between Pulmonary function, physical activities, Borg scale, and QOL is novel.

Many pieces of evidence showed that lung resection had a significant impact on respiratory function, and the deficits may reduce the patients' QoL $[3,5]$. However, Brunelliet al. found that QoL had a poor correlation with FEV1 and CO lung diffusion capacity [3]. In the present study, we also showed that FVC was not related to QoL. Noting that FVC was positively associated with the general health, vitality, and role-emotional scales of the SF-36, those results indicated that FVC only affected a few functioning scales and could not be taken as surrogates for QOL evaluation [11]. Because the indirect effects from FVC to QoLwere observed in our study, pulmonary function-enhancing intervention may be useful in improving quality of life in patients with resected lung cancer.

Wolkoveet al. reported that dyspnea is poorly correlated with pulmonary function in patients with obstructive lung disease [14]. In the present study, we found that Borg scales were positively associated with physical activities from our mediation model. Furthermore, the main negative relationship between Borg scales and the domains of the SF-36 was physical functioning and role-physical in this study. And the worsening dyspnea caused patients to reduce their physical activities [15]. Those results indicated that Borg dyspnea scaleswere preferred to describe the physical status.

Lung cancer survivors always experience QoL impairments, and engagement in physical activity is associated with better QoL. Also, physical activity was independently associated with QoL in lung cancer patients withpost-curative-intent treatment [8]. We also found that 6MWD was associated with QoL but the significance level was $P=0.044$. However, $6 \mathrm{MWD}$ recovery in elderly patients after lung cancer surgery was not related to their health-related QOL recoveries [4]. One of the possible reasons for the inconsistent results is that the effect of physical activity on QoL is indirect. Our results confirmed the possibility and an indirect effect between QoL with physical activities were observed.

Cardiorespiratory fitness is determined mainly by aerobic physical activity, and CRF is strong associated with the physical dimensions of health-related QoL [16]. In our study, CRF (VT and $\mathrm{VO}_{2 \max }$ ) was positively associated with the physical dimensions except for the pain of QoL, and CRF had a direct effect on QoL. In fact, muchevidence showed that there was a strong correlation between 6MWT [6], pulmonary function [4], and CRF. Our results clearly showed that the relationship between physical activity, pulmonary function, and QoL was significantly mediated by CRF in patients with lung cancer resection. This result was similar to the previous works that CRF mediated the effects of 12-week aerobic exercise on general fatigue in a woman with systemic lupus erythematosus [17]. As a mediator, CRF also affected the effects of a Mediterranean diet on the mental component summary of QoL. In our study, CRF $\left(\mathrm{VT}^{\mathrm{and}} \mathrm{VO}_{2 \mathrm{max}}\right)$ was positively associated with 3 out of 4 mental domains of QoL. 
In the clinic, QoL in patients with resected lung cancer was poor. Poor QoL means difficulty for these kinds of patients to deal with a range of deficits or limitations related to cognitive, psychosocial, physical, sensory functioning, and other aspects of performance [18]. The results in the present study showed that only 38.5\% of the changes in QoLwere due to CRF. Thus, the improving QoL program for the patients with lung resection not only focuses on how to improve CRT, but also pays more attention to other impact factors.

With regard to the limitations of this study, the small number of patients $(n=38)$ means that the study lacked statistical strength. Second, some other factors that could affect QoL in patients with resected lung cancer were not included in our structural equation modelings such as family supportand economic level. Third, this was a single-center study.

In conclusion, CRF has a direct effect on the quality of life in patients with resected lung cancer. Furthermore, CRT, as mediated variably, can mediate the relationship between pulmonary function, physical activity, Borg dyspnea, and quality of life. In the future, more attention to improving CRT is needed for improving the quality of life of patients with resected lung cancer.

\section{Declarations}

Conflicts of interest: The authors have no conflicts of interest to declare.

Funding: This work was supported by Basic Research Grant from national natural science foundation of China [No. 81972142, No. 81871857].

Acknowledgments: None

A data availability statement: All data generated and/or analyzed during the present study are included in this article.

Contributions: XP Li drafted the first version of the manuscript. All authors were involved in all stages of the study design and data collecting, and submission to ethical committee was done by MS Zhang. XP Li and MS Zhang were involved in statistical analysis. All authors read and approved the final version of the manuscript.

Ethics approval: This study was performed according to the declaration of Helsinki and was approved by the Guangdong provincial people's Hospital (No. 2012124H(R2)).

Patient consent for publication: All patients provided written patient consent for publication.

\section{References}

1. Siegel RL, Miller KD, JemalA.Cancer statistics, 2019. CA Cancer J Clin. 2019;69(1):7-34. doi: 10.3322/caac. 21551. 
2. Hong-Lin, Chen Kun Liu,Qing-Sheng You. Self-efficacy, cancer-related fatigue, and quality of life in patients with resected lung cancer. Eur J Cancer Care (Engl). 2018;27(6):e12934.doi:

10.1111/ecc.12934.

3. Brocki BC, Westerdahl E, Langer D, Souza DSR, Andreasen JJ. Decrease in pulmonary function and oxygenation after lung resection.ERJ Open Res. 2018;4(1):00055-2017. doi:

10.1183/23120541.00055-2017.

4. Hiroshi Saito, Atsushi Shiraishi, Hiroaki Nomori, Hiroki Matsui, Kazuki Yoshida, Yuya Matsue, Tomoko Fujii, KennosukeKawama. Impact of age on the recovery of six-minute walking distance after lung cancer surgery: a retrospective cohort study. Gen ThoracCardiovasc Surg. 2020;68(2):150157. doi: 10.1007/s11748-019-01191-7.

5. Szeliga E, Czenczek-Lewandowska E, Kontek A, Wolan-Nieroda A, Guzik A, Walicka-Cupryś K. Evaluation of the quality of life after surgical removal of lung cancer.AdvRespir Med. 2019;87(1):1419. doi: 10.5603/ARM.a2019.0003.

6. Olga Marieke de Vries, Heidi Johansen, Svein Otto Fredwall. Physical fitness and activity level in Norwegian adults with achondroplasia. Am J Med Genet. 2021;185(4):1023-1032. doi: 10.1002/ajmg.a.62055.

7. Engberg E, Tikkanen HO, Koponen A, Hägglund H, Kukkonen-Harjula K, Tiitinen A, Peltonen JE, Pöyhönen-Alho M. Cardiorespiratory fitness and health-related quality of life in women at riskfor gestational diabetes. Scand J Med Sci Sports. 2018;28(1):203-211. doi: 10.1111/sms.12896.

8. Duc Ha, Andrew L Ries, Peter J Mazzone, Scott M Lippman, Mark M Fuster .Exercise capacity and cancer-specific quality of life following curative intent treatment of stage I-IIIA lung cancer. Support Care Cancer. 2018;26(7):2459-2469. doi: 10.1007/s00520-018-4078-4.

9. Ware JE Jr, Gandek, B. Overview of the SF-36 Health Survey and the International Quality of Life Assessment (IQOLA) Project. J ClinEpidemiol. 1998: 51: 903-912.

10. Miller MR, Hankinson J, Brusasco V, Burgos F, Casaburi R, Coates A, Crapo R, Enright P, van der Grinten CP, Gustafsson P, Jensen R, Johnson DC, Maclntyre N, McKay R, Navajas D, Pedersen OF, Pellegrino R, Viegi G, Wanger J; ATS/ERS Task Force. Standardisation of spirometry. EurRespir J. 2005;26(2):319-38. doi: 10.1183/09031936.05.00034805.

11. Brunelli A, Socci L, Refai M, Salati M, Xiumé F, Sabbatini A. Quality of life before and after major lung resection for lung cancer: a prospective follow-up analysis. Ann Thorac Surg. 2007;84(2):410-6. doi: 10.1016/j.athoracsur.2007.04.019.

12. Ari Mänttäri, JaanaSuni, HarriSievänen, PauliinaHusu, Henri Vähä-Ypyä, Heli Valkeinen, Kari Tokola, TommiVasankari. Six-minute walk test: a tool for predicting maximal aerobic power (VO2 max) in healthy adults. PhysiolFunct Imaging. 2018. doi: 10.1111/cpf.12525.

13. Preacher KJ, Hayes AF. Asymptotic and resampling strategies for assessing and comparing indirect effects in multiple mediator models. Behav Res Methods. 2008;40(3): 879-891.

14. N Wolkove, E Dajczman, A Colacone, $\mathrm{H}$ Kreisman. The relationship between pulmonary function and dyspnea in obstructive lung disease. 1989 Dec;96(6):1247-51. doi: 10.1378/chest.96.6.1247. 
15. Janet $L$ Larson, Margaret K Covey, Susan Corbridge. Inspiratory muscle strength in chronic obstructive pulmonary diseas AACN Clin Issues. 2002;13(2):320-32. doi: 10.1097/00044067200205000-00015.

16. Olga Marieke de Vries, Heidi Johansen, Svein Otto Fredwall. Physical fitness and activity level in Norwegian adults with achondroplasia. Am J Med Genet A. 2021;185(4):1023-1032. doi: 10.1002/ajmg.a.62055.

17. Blanca Gavilán-Carrera, José Antonio Vargas-Hitos, Pablo Morillas-de-Laguno, Antonio RosalesCastillo, Sergio Sola-Rodríguez, José Luis Callejas-Rubio, José Mario Sabio, Alberto SorianoMaldonado. Effects of 12-week aerobic exercise on patient-reported outcomes in women with systemic lupus erythematosus. DisabilRehabil. 2020;1-9. doi: 10.1080/09638288.2020.1808904.

18. Ping Yang, Andrea L Cheville, Jason A Wampfler, Yolanda I Garces, Aminah Jatoi, Matthew M Clark, Stephen D Cassivi, David E Midthun, Randolph S Marks, Marie-Christine Aubry, Scott H Okuno, Brent A Williams, Francis C Nichols, Victor F Trastek, Hiroshi Sugimura, Linda Sarna, Mark S Allen, Claude Deschamps, Jeff A Sloan. Quality of life and symptom burden among long-term lung cancer survivors. J ThoracOncol. 2012;7(1):64-70. doi: 10.1097/JT0.0b013e3182397b3e.

\section{Figures}

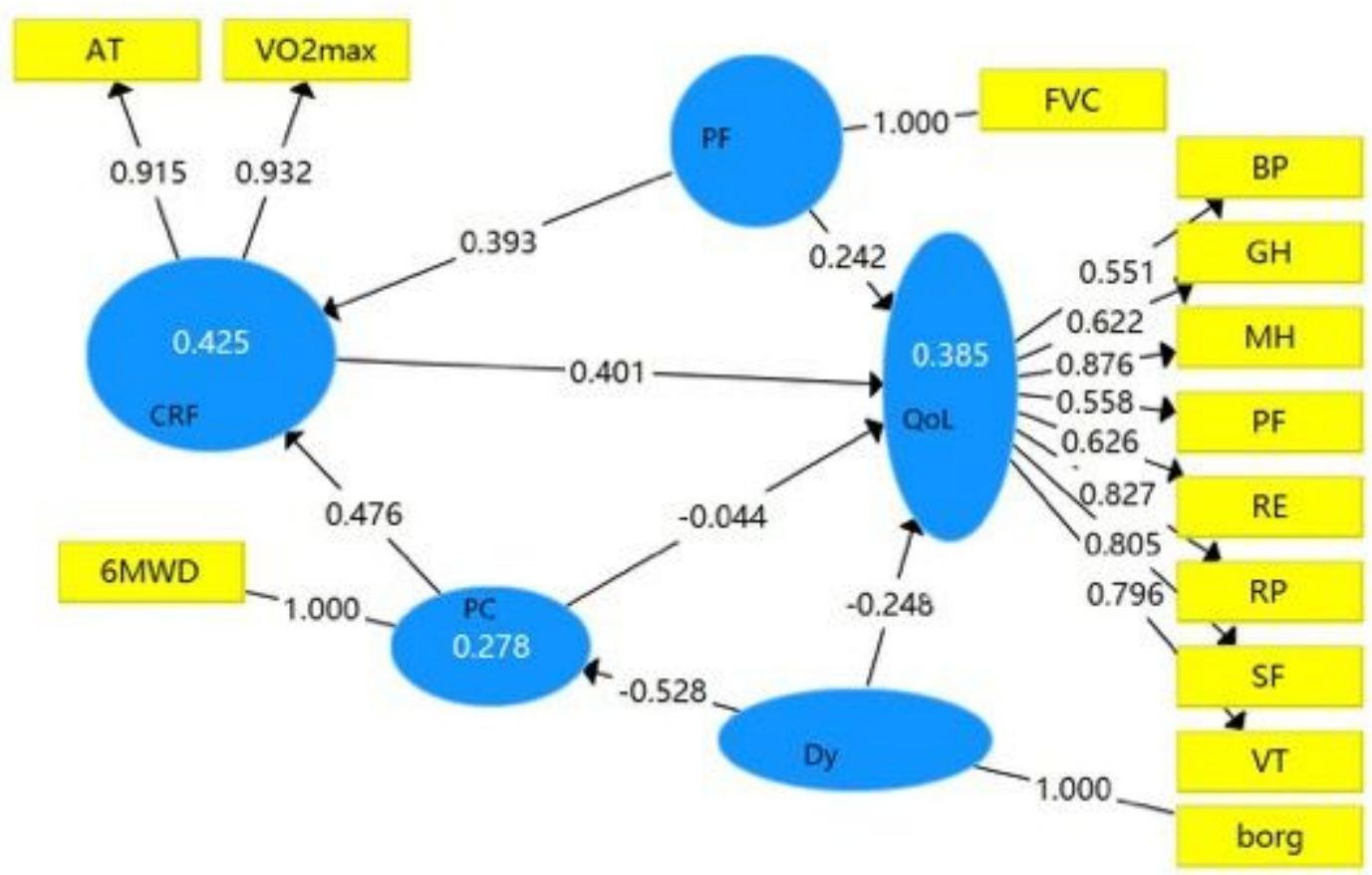

\section{Figure 1}

Structural model: Exploring the paths model to quality of life.Dy, dyspnea; PC, physical capacity; $\mathrm{CRF}$,Cardiorespiratory fitness; PF, pulmonary function; QoL, quality of life 
A: Basic model

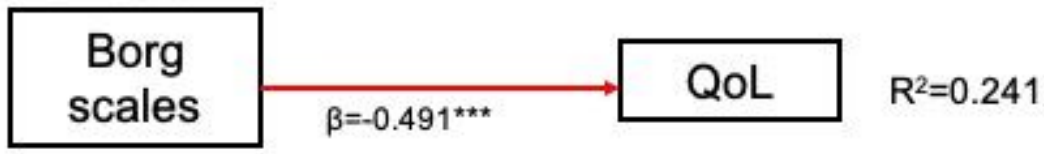

B: Mediation model (indirect effect)
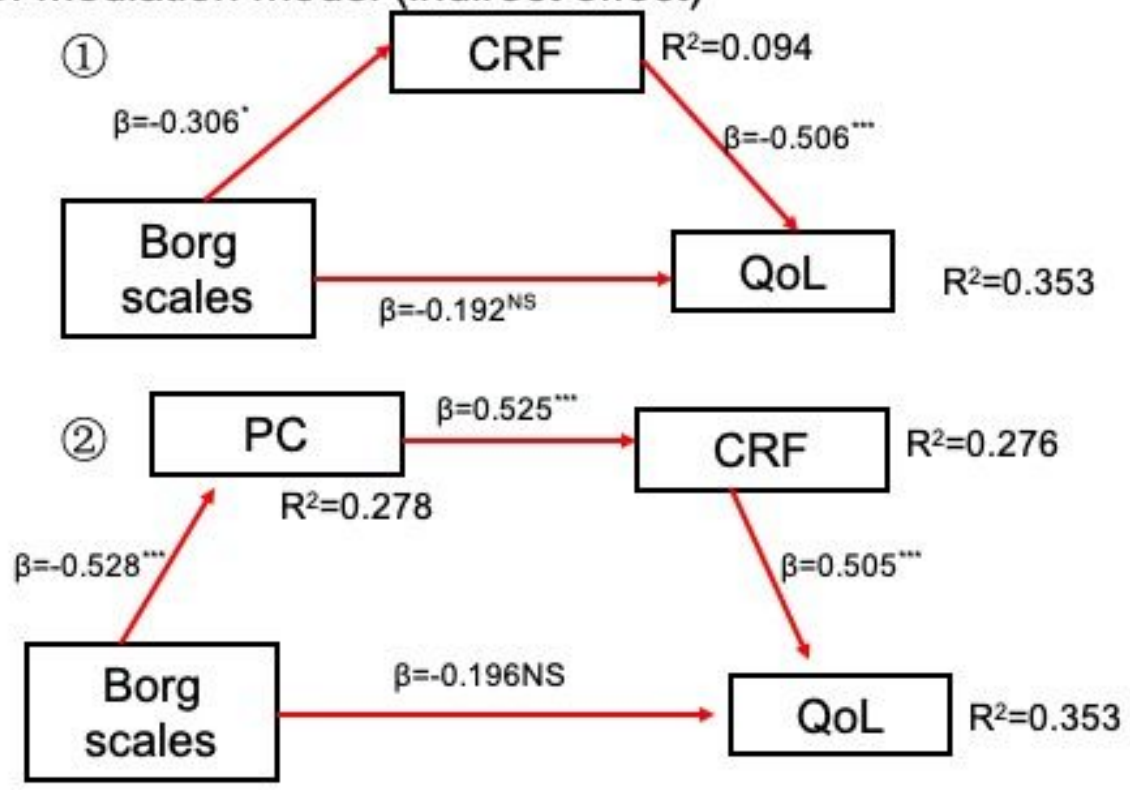

${ }^{\star} p<0.05 ;{ }^{\star \star} p<0.01 ;{ }^{\star \star \star} p<0.001 ; N S=$ not significant

PC, physical capacity; CRF,Cardiorespiratory fitness; QoL, quality of life

Figure 2

Mediating effect of Borg scale on quality of life, via PC and CRF

A: Basic model

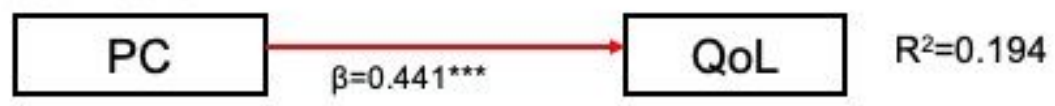

B: Mediation model (indirect effect)

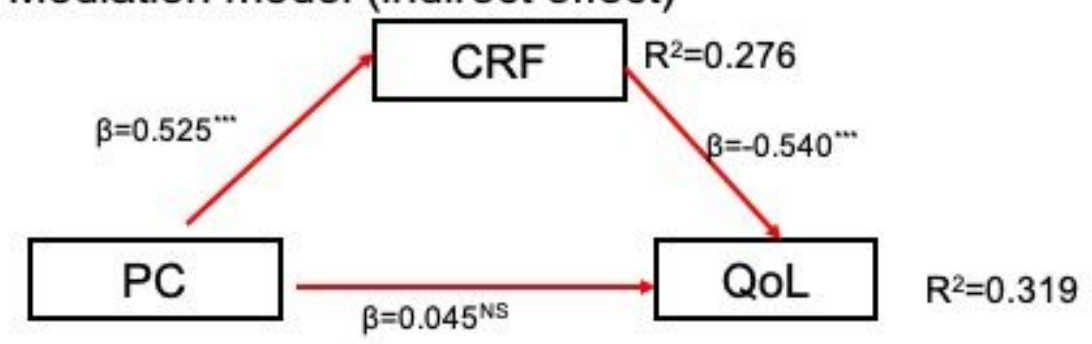

${ }^{\star} p<0.05 ;{ }^{* \star} p<0.01 ;{ }^{\star \star \star} p<0.001$; NS=not significant

PC, physical capacity; CRF, Cardiorespiratory fitness; QoL, quality of life

\section{Figure 3}

Mediating effect of physical capacity on quality of life, via CRF. 
A: Basic model

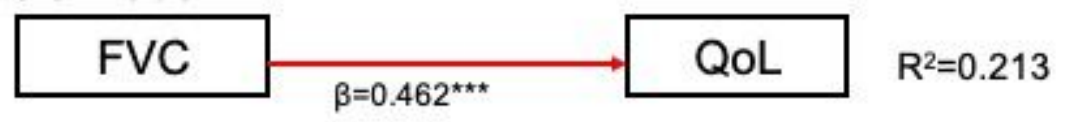

B: Mediation model (indirect effect)

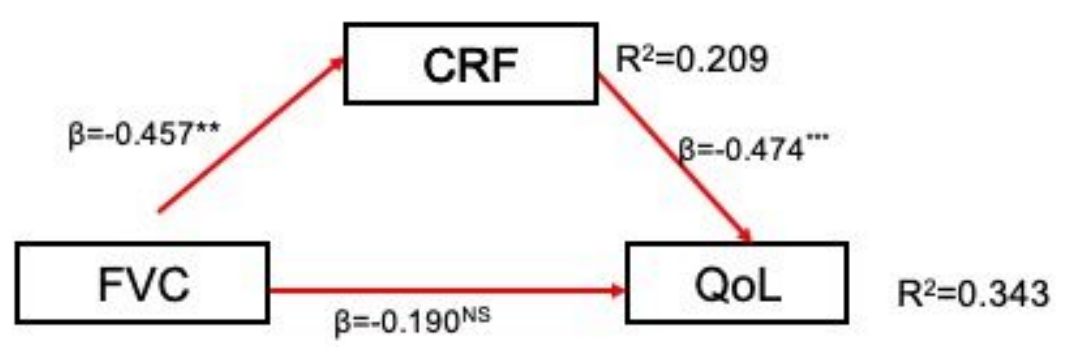

${ }^{\star} p<0.05 ;{ }^{* \star} p<0.01 ;{ }^{\star \star \star} p<0.001$; NS=not significant

CRF, Cardiorespiratory fitness; FVC, forced vital capacity; QoL, quality of life

\section{Figure 4}

Mediating effect of pulmonary function on quality of life, via CRF. 